\title{
Prenatal Immune Challenge Disrupts Sensorimotor Gating in Adult Rats: Implications for the Etiopathogenesis of Schizophrenia
}

José Borrell, Ph.D., José Miguel Vela, Ph.D., Angel Arévalo-Martin, Eduardo Molina-Holgado, Ph.D., and Carmen Guaza, Ph.D.

Increasing evidence associates schizophrenia with prenatal exposure to infection. Impaired ability to "gate out" sensory and cognitive information is considered to be a central feature of schizophrenia and is manifested, among others, in disrupted prepulse inhibition (PPI) of the acoustic startle reflex. We analyzed the effect of a prenatal immune challenge- peripheral administration of bacterial endotoxin lipopolysaccharide (LPS) to pregnant female rats-upon PPI and immune function in adult offspring. Prenatal LPS treatment disrupted PPI which was reversed by antipsychotics. Serum levels of interleukin-2 and interleukin-6 were increased. In addition, histopathological features in brain areas related with PPI circuitry were observed. These results illustrate the critical influence of prenatal immune events upon adult CNS functioning in association with the putative role of the immune system in the etiopathogenesis of schizophrenia.

[Neuropsychopharmacology 26:204-215, 2002]

(C) 2002 American College of Neuropsychopharmacology. Published by Elsevier Science Inc.
KEY WORDS: Prepulse inhibition; Immune challenge; Schizophrenia; Antipsychotics; Cytokines; Rat

Pronounced sensorimotor gating abnormalities have been reported in schizophrenic patients (Braff et al. 1978; Kumari et al. 1999). A well-established sensorimotor gating paradigm is the prepulse inhibition (PPI) of the startle response. PPI refers to the reduction in startle

From the Psychobiology Group, Neural Plasticity Department, Cajal Institute, 28002 Madrid, Spain (JB, AA-M, EM-H, CG), and Unit of Histology, School of Medicine, Department of Cell Biology, Physiology and Immunology, Autonomous University of Barcelona, Bellaterra, 08193 Barcelona, Spain (JMV)

Address correspondence to: Dr. José Borrell, Ph.D., Cajal Institute, 28002 Madrid, Spain, E-mail: cgjb@cajal.csic.es

Received January 24, 2001; revised May 22, 2001; accepted August 5, 2001.

Online publication: $8 / 21 / 01$ at www.acnp.org/citations/ Npp082101167. reactivity toward an intense pulse stimulus when it is shortly preceded by a weak prepulse stimulus (Hoffman and Ison 1980). It is thought that the prepulse response activates an inhibitory process that attenuates or "gates" the startle response. Because identical stimulus parameters can be used for animal and human studies, it is considered that animal models of PPI disruption represent a promising way to study the neural mechanisms underlying sensorimotor gating dysfunction (Swerdlow et al. 1994, 1999; Swerdlow and Geyer 1998) and as a screening test for potential antipsychotics (Swerdlow et al. 1994; Depoortere et al. 1997). In fact, antipsychotics remove PPI deficits in schizophrenic patients (Kumari et al. 1999; Weike et al. 2000). Nevertheless, it must be taken into consideration that deficiency of PPI has been reported in other selected neuropsychiatric disorders where inability to inhibit movements is involved (Huntington's disease (Swerdlow et al. 1995), 
Tourette's syndrome (Castellanos et al. 1996)), where inability to control attentional and cognitive processes is involved (obsessive-compulsive disorder (Swerdlow et al. 1993)), or where anxiety and exaggerated startle occur (posttraumatic stress disorder (Grillon et al. 1996)).

The focus of schizophrenia research has been turning from studies of structural and functional brain abnormalities to an increasing emphasis on possible etiologic factors. Neurodevelopmental theories of schizophrenia postulate that the psychopathology of schizophrenia may derive from alterations of brain organization secondary to defective ontogenesis (Weinberger 1996; Raedler et al. 1998). A causal relationship pertaining to disturbed brain ontogenesis and schizophrenia comes from epidemiological studies that have identified several risk factors that, acting during pregnancy, increase the incidence of the disease in offspring. Maternal infection with influenza virus in the second trimester of pregnancy causes a major disorder incidence (Mednick et al. 1988; O'Callaghan et al. 1991; Adams et al. 1993). In addition, a seasonal effect has been also documented, with more persons born in the late winter and early spring months developing schizophrenia (Torrey et al. 1977; Mortensen et al. 1999).

Release of cytokines by cells from the immune system is a hallmark in the response to infection. Accumulating experimental and clinical evidence suggest the involvement of cytokines in CNS development and function as well as in many pathological conditions (Plata-Salamán 1991; Otero and Merrill 1994; Rothwell and Hopkins 1995; Raber et al. 1998; Zao and Schwartz 1998). Systemic administration of the bacterial endotoxin lipopolysaccharide (LPS) is a widely used and accepted model to emulate immune activation and subsequent release of immunoregulatory, cytotoxic and inflammatory cytokines secondary to gram-negative bacterial infections (Dinarello 1984; Andersson et al. 1992). Administration of LPS or pro-inflammatory cytokines causes pronounced centrally mediated effects, such as changes in body temperature (Linthorst et al. 1994; Pauli et al. 1998), sleep (Pollmächer et al. 1993), neuroendocrine function (Besedovsky et al. 1986; Berkenbosch et al. 1987; Cambronero et al. 1992; Linthorst et al. 1994, 1995; Molina-Holgado et al. 1996; Pauli et al. 1998) and behavior (del Cerro and Borrell 1990; Kent et al. 1992; Linthorst et al. 1995; Anisman et al. 1998; Hanisch et al. 1997; Pauli et al. 1998; Zalcman et al. 1998).

To investigate the putative effect of a prenatal immune challenge on sensorimotor gating, a new experimental design was developed consisting in the administration of LPS to pregnant rats followed by evaluation of PPI in the adult offspring. We show that prenatal LPS treatment disrupts sensorimotor gating later in life. This effect is overcome by antipsychotic treatment. In addition, circulating interleukin-2 (IL-2) and interleukin-6 (IL-6) levels are increased, which coincide with some of the immunological alterations described in schizophrenic patients. Histopathological alterations in brain structures involved in the processing of sensorimotor gating are also observed, and, to some extent, resemble those described in schizophrenia.

\section{MATERIALS AND METHODS}

\section{Experimental Animals}

Procedures involving animals and their care were conducted in conformity with national and international laws and policies. Wistar rats from our inhouse colony were used. They were kept under standard conditions $\left(22 \pm 2^{\circ} \mathrm{C}, 12: 12 \mathrm{~h}\right.$ light/dark cycle; lights on at 7:00 A.M.) and received food and water ad libitum.

\section{Prenatal Administration of LPS}

Vaginal smears were taken daily from breeder females and, when found in estrus, females were placed with males of the same strain. Pregnancy was determined the next morning by the presence of sperm in the vaginal smear (= day 0 of pregnancy). LPS (Lipopolysaccharide from Escherichia coli, Sigma L-3755 Serotype 026:B6) was subcutaneously (s.c.) administered to pregnant rats in a dose of $1 \mathrm{mg} / \mathrm{kg}$ on alternate days during pregnancy. LPS was dissolved in saline and injected in a volume of $1.5 \mathrm{ml} / \mathrm{kg}$. Control groups consisted of pregnant rats submitted to the same treatment schedule with saline. Animals were submitted to LPS or vehicle treatment at different seasons of the year during 14 months.

In the first experiment, offspring obtained from three different groups of three pregnant rats each injected with LPS and three different groups of three pregnant rats each injected with saline were used. Male and female groups of 9-11 rats, exposed prenatally to LPS or vehicle, were tested for prepulse inhibition of acoustic startle response when they reached the age of 55-65 (60day groups), 100-115 (100-day groups) and 290-310 (300-day groups) days. Another four groups (two control and two LPS-exposed) of eight male and eight female offspring of the 60 and 300-day groups were sacrificed at the corresponding time periods. Animals were tested for PPI and sacrificed 8-10 days later by decapitation with the aid of a guillotine and trunk blood was collected. Serum was prepared by centrifugation at $15,000 \times \mathrm{g}$ for $5 \mathrm{~min}$ and aliquoted for cytokines and corticosterone assays. Three male rats of the 60 and of the 300 -day groups together with the same number of the corresponding control males were used for histological studies. 
In the second experiment, offspring obtained from five pregnant rats injected with LPS and five pregnant rats injected with saline were submitted, when they reached the age of 90-110 days, to administration of a single dose of $0.1 \mathrm{mg} / \mathrm{kg}$ (s.c.) of haloperidol (HAL), 5 $\mathrm{mg} / \mathrm{kg}$ (i.p.) of clozapine (CZP), or the corresponding vehicles $30 \mathrm{~min}$ before PPI testing. Clozapine (Sigma C 6305) and Haloperidol (Sigma H 1512) were dissolved in a few drops of acetic acid and final volume made up with distilled water. The $\mathrm{pH}$ was adjusted to about 5 with $1 \mathrm{M} \mathrm{NaOH}$. All drugs were injected in a volume of $1.5 \mathrm{ml} / \mathrm{kg}$.

\section{Adult Administration of LPS}

In order to evaluate the acute immunological effects of the LPS treatment followed in the previous experiments, female adult rats (weight 225-275g) were submitted to subcutaneous administration of a single dose of $1 \mathrm{mg} / \mathrm{kg}$ of LPS (prepared as mentioned above) and sacrificed 40, 80 or 120 min after injection. Control animals receiving the corresponding dose of vehicle were sacrificed at the same time intervals. Animals were sacrificed by decapitation with the aid of a guillotine and trunk blood was collected. Serum was prepared by centrifugation at $15,000 \times \mathrm{g}$ for $5 \mathrm{~min}$ and divided up for cytokines and corticosterone assays.

\section{ELISA and RIA Detection Assays}

Serum IL-1 $\beta$ was measured using enzyme-linked immunoadsorbent assay (interleukin-1 $\beta$, rat, ELISA system, Biotrak, Amersham Pharmacia Biotech, Buckinghamshire, UK); the detection limit was $8 \mathrm{pg} / \mathrm{ml}$. Serum IL-6 was measured using ELISA (interleukin-6 rat, Biotrak, Amersham Pharmacia Biotech); the detection limit was $10 \mathrm{pg} / \mathrm{ml}$. Serum IL-2 was measured using ELISA (interleukin-2 rat Immunoassay Kit, Cytoscreen, BioSource International, Camarillo, CA); the detection limit was $5 \mathrm{pg} / \mathrm{ml}$. Corticosterone was measured in serum using a solid phase ${ }^{125}$ I radioimmunoassay (Coat-ACount Rat Corticosterone kit, Diagnostic Products Corp., Los Angeles, CA); the detection limit was $5.7 \mathrm{ng} / \mathrm{ml}$.

\section{Histology}

Animals were anesthetized with sodium pentobarbital $(50 \mathrm{mg} / \mathrm{kg}$ ) and transcardially perfused with $4 \%$ paraformaldehyde in $0.1 \mathrm{M}$ phosphate buffer. Brains were removed, immersed in fixative for $4 \mathrm{~h}$, cryoprotected in $30 \%$ sucrose and frozen with dry $\mathrm{CO}_{2}$. Series of coronal sections (40 $\mu \mathrm{m}$ thick) were obtained using a cryostat and processed either for glial fibrillary acidic protein (GFAP) immunocytochemistry to visualize astrocytes, for tomato lectin histochemistry and OX-42 immunocytochemistry to visualize microglia/macrophages, for
OX-6 immunocytochemistry to detect expression of major histocompatibility complex class II molecules (MHC class II), or for tyrosine hydroxylase (TH) immunocytochemistry to visualize catecholaminergic pathways. Briefly, endogenous peroxidase activity was blocked with $2 \%$ hydrogen peroxide in $100 \%$ methanol for 10 min, sections were treated for $30 \mathrm{~min}$ with $10 \%$ fetal calf serum to prevent unspecific protein binding and incubated overnight at $4^{\circ} \mathrm{C}$ with 1:1200 mouse monoclonal anti-GFAP (Sigma G 3893), 10 $\mu \mathrm{g} / \mathrm{ml}$ biotinylated tomato lectin (Lycopersicon esculentum; Sigma L0651), 1:200 mouse monoclonal anti-rat CD11b (OX-42, Serotec MCA275G), 1:200 mouse monoclonal anti-rat Ia (OX-6, Serotec MCA46R), or 1:500 rabbit anti-TH (Chemicon MAB358). Secondary anti-mouse or anti-rabbit IgG-biotinylated antibodies (Amersham RPN1001, RPN1004) diluted to 1:200 and avidin-peroxidase (Sigma A 3151) diluted to 1:600 were incubated for one hour at room temperature. The peroxidase reaction product was visualized using DAB as chromogen. Possible changes in TH immunoreactivity were assessed by quantifying the density of $\mathrm{TH}$ immunostaining within selected nuclei. For this study, brain sections from control and LPS-treated male rats of 100 and 300 days of age, at levels containing accumbens and bed nucleus of the stria terminalis, were simultaneously processed for TH immunohistochemistry in order to avoid methodological changes affecting the intensity of staining. Appropriate fields were digitized by a video camera connected to a Leitz microscope and interfaced to a Macintosh computer. The boundary of each nuclei was traced and the mean density was measured based on the computer grayscale (from $0=$ white to 255 = black) by using the National Institute of Health Image software (NIH 1.62).

\section{PPI Testing}

The startle device consisted of a non-restrictive Plexiglas cage $(28 \times 15 \times 17 \mathrm{~cm})$ which encloses the sensor's platform but does not touch it. If the animal moves up or down, a transient force is developed on the platform. This transient force is measured at its peak, being the measure of the amplitude of the startle response. Startle movements of the rat were transduced by an accelerometer (Cibertec S.A., Madrid, Spain) and the signal was sampled and digitized by a microcomputer, which also served for to present stimuli, and to record data. The startle device was located in a sound-attenuating chamber $(90 \times 55 \times 60 \mathrm{~cm})$ constantly illuminated $(10 \mathrm{~W}$ lamp) and equipped with a loudspeaker located in the top of the chamber which constantly provided a $45 \mathrm{dBA}$ background white noise. Two $28 \mathrm{~cm}$ loudspeakers (Cibertec S.A., Madrid, Spain) located $15 \mathrm{~cm}$ from both sides of the Plexiglas cage produced the various acoustic stimuli. These speakers were connected to an audio- 
amplifier (Cibertec S.A., Madrid, Spain) which, in turn was connected to a noise generator (2001 Function Generator, Columbus, $\mathrm{OH}$, USA) which provided the acoustic startle stimulus and to a second noise generator (BF-1 Retex, Madrid, Spain) which provided the auditory signal corresponding to the auditory prepulse. The acoustic startle stimulus was a pure tone pulse of $20 \mathrm{kHz}, 100 \mathrm{msec}$ duration $(10 \mathrm{msec}$ rise and decay times), of $100 \mathrm{dBA}$ intensity. The auditory prepulse stimulus was a pure tone pulse of $250 \mathrm{~Hz}, 50 \mathrm{msec}$ duration ( $5 \mathrm{msec}$ rise and decay times) at an intensity of 55 $\mathrm{dBA}$ ( $10 \mathrm{~dB}$ above the background noise), delivered 100 msec before the acoustic startle stimulus. Sound measurements were made within the Plexiglas cage using a sound level meter (Brüel and Kjaer, Darmstad, Germany). The light stimulus corresponding to the visual prepulse stimulus was produced by a xenon lamp located $30 \mathrm{~cm}$ above the top of the Plexiglas cage. This lamp was connected to a photic stimulator (FF-40, Cibertec S.A., Madrid, Spain). The visual prepulse stimuli consisted of a photic stimulus of $20 \mathrm{msec}$ duration, with near instantaneous rise and decay times delivered 100 msec prior the acoustic startle stimulus.

Rats were placed in the startle chamber and $5 \mathrm{~min}$ later presented with 30 startle eliciting stimuli alone (100 dBA). These initial startle pulses produce some habituation, which reduce variability and stabilize baseline startle amplitude (Campeu and Davis 1995), but they were not used in the estimation of prepulse inhibition. Thirty seconds following the last initial startle stimulus, 60 additional $100 \mathrm{dBA}$ startle stimuli were presented, consisting of 20 startle stimuli alone (Pulse alone trials), 20 startle stimuli occurring after the auditory prepulse (Auditory prepulse + pulse trials), and 20 startle stimuli occurring after the visual prepulse (Visual prepulse + pulse trials). The startle stimuli were presented at a fixed interstimulus interval of $30 \mathrm{~s}$ and the occurrence of each trial type was semirandom with the restriction that each trial type had to occur in every three trial blocks.

\section{Data Analysis}

The amount of PPI is expressed as the percentage decrease in the amplitude of the startle response caused by presentation of the prepulse, and degree of prepulse inhibition (\%) was calculated according to the formula: (100-(startle amplitude on prepulse + pulse trials/startle amplitude on pulse alone trials) $\times 100$ ). Percentage scores were used in order to minimize the effect of individual variation of startle amplitude on PPI (Mansbach et al. 1988). Using this description of PPI, a high degree of sensorimotor gating is reflected in a high \% PPI value, whereas less or no gating results in a small or negative $\%$ PPI value.
The data are presented as mean \pm S.E.M. Data were analyzed for the effects of prenatal treatment, sex, age and drug treatment by analysis of variance (ANOVA) using SPSS, followed by the posteriori Student-Newman-Keuls $t$-test when appropriate. The criterion for significance was set at $p<.05$.

\section{RESULTS}

\section{Effect of Prenatal LPS Exposure upon PPI}

PPI was determined by measuring the decrement in the startle response when the acoustic startle-eliciting stimulus was preceded by an auditory or visual prepulse (PP). Figure 1 shows, in prenatally LPS-exposed male and female rats at three different ages (60, 100 and 300 days) and in the corresponding control animals, startle amplitude during pulse alone trials (upper panels) and percentage of PPI (medium and lower panels).

In control animals, statistical analysis revealed no significant effect of sex $\left(\mathrm{F}_{1,56}=2.854, \mathrm{NS}\right)$, age $\left(\mathrm{F}_{2,56}=\right.$ $1.870, N S)$ or sex $X$ age interaction $\left(F_{2,56}=0.253, N S\right)$ upon basal startle reactivity (Figure 1, Panel A). Analysis of percentage of PPI in control animals revealed that visual prepulse (Figure 1, Panel C) induced significantly higher degree of inhibition than auditory prepulse (Figure 1, Panel B) $\left(\mathrm{F}_{1,56}=83.155, p<.001\right)$. A significant effect of age $\left(\mathrm{F}_{2,56}=14.028, p<.001\right)$ was detected. Post hoc tests indicated that, for both sexes, rats of 60 days displayed significantly lower PPI than rats of 100 or 300 days of age. No sex differences were observed $\left(\mathrm{F}_{1,56}=\right.$ 0.858, NS).

Analysis of the data corresponding to adult offspring of rats submitted to LPS treatment during pregnancy (LPS-exposed rats) revealed that prenatal LPS treatment did not significantly affect baseline startle amplitude $\left(\mathrm{F}_{1,113}=2.471, \mathrm{NS}\right)$. However, a significant effect of sex was apparent $\left(\mathrm{F}_{1,113}=13.638, p<.001\right)$ (Figure 1, Panel A). LPS-exposed male rats displayed a slightly, but significant $\left(\mathrm{F}_{1,56}=7.037, p<.05\right)$ lower basal startle reactivity than the corresponding controls, at variance to LPS-exposed female rats $\left(\mathrm{F}_{1,57}=0.001, \mathrm{NS}\right)$. Concerning the PPI data (Figure 1, Panels B and C), statistical analysis revealed a significant PP type $X$ treatment $X$ age $X$ sex interaction $\left(F_{2,113}=3.226, p<.05\right)$, as well as a significant $P P$ type $X$ treatment $X$ sex interaction $\left(\mathrm{F}_{1,113}=\right.$ 21.071, $p<.001)$, and PP type $X$ treatment $X$ age interaction $\left(\mathrm{F}_{2,113}=4.148, p<.05\right)$. The effect of prenatal LPS treatment was significantly higher upon auditory than visual PPI $\left(\mathrm{F}_{1,113}=9.010, p<.01\right)$, and on male than female offspring $\left(\mathrm{F}_{1,113}=15.818, p<.001\right)$. A significant PP type $\mathrm{X}$ age interaction $\left(\mathrm{F}_{1,113}=16.764, p<.001\right)$ was also observed. LPS-exposed male rats displayed significantly lower auditory and visual PPI than the corresponding controls at all ages tested, whereas LPSexposed female rats showed significantly lower auditory 
MALE

A.

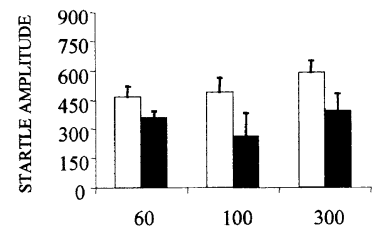

B.

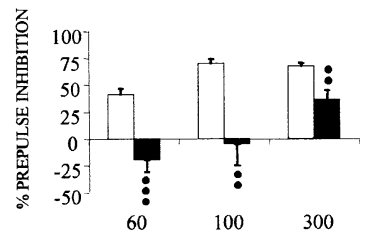

C.

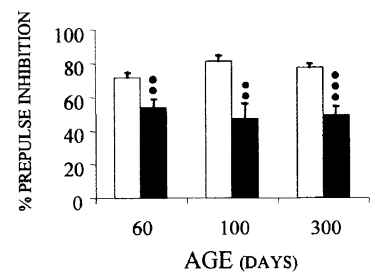

CONTROL

Figure 1. Effect of prenatal administration of LPS on startle amplitude (A) and percentage of auditory (B) and visual (C) prepulse inhibition in male and female adult $(60,100$ or 300 days of age) rats. LPS-exposed groups consisted of offspring rats whose mothers were subjected to administration of a dose of $1 \mathrm{mg} / \mathrm{kg}$ (s.c.) of LPS on alternate days during pregnancy. Control groups consisted of offspring rats whose mothers were submitted to the same treatment schedule with saline. Startle responses were recorded to 20 repetitions of either: (A) a $100 \mathrm{msec}, 100 \mathrm{dBA}$ tone (pulse alone trials). or (B) a $50 \mathrm{msec}, 55 \mathrm{dBA}$ tone (auditory prepulse trials), or (C) a $20 \mathrm{msec}$ photic stimulus (visual prepulse trials), given 100 msec prior to the $100 \mathrm{dBA}$ startling stimulus. Mean startle amplitudes (in arbitrary units) for each trial type were calculated for individual animals. Data for each animal were transformed such that its mean prepulse + pulse startle response was expressed as percentage decrease from its mean startle response to the pulse-alone value. Note that higher percentage values of PPI indicate a higher degree of sensorimotor gating (i.e., the prepulse greatly inhibits the response to the startling stimulus) than do lower values. Results are expressed as mean \pm S.E.M. $(n=9-11$ rats per group). ${ }^{\cdot} p<.05 ;{ }^{*} p<.01 ;{ }^{\cdots} p<.001$ vs. corresponding CONTROL group (Student-Newman-Keuls $t$-test following significant ANOVA).

and visual PPI than the corresponding controls only at 100 and 300 days of age.

Therefore, prenatal LPS exposure disrupts PPI later in life. It is important to note that under the LPS treat- ment schedule followed in pregnant rats, normal weight during maturation of the offspring was observed (data not shown). ANOVA of the data, although it obviously showed a significant effect of $\operatorname{sex}\left(\mathrm{F}_{1,113}=\right.$ 426.060, $p<.001)$, age $\left(\mathrm{F}_{2,113}=312.279, p<.001\right)$ and sex $\mathrm{X}$ age interaction $\left(\mathrm{F}_{2,113}=29.266, p<.001\right)$ upon animal weight, failed to reveal any significant effect of treatment $\left(\mathrm{F}_{1,113}=1.713, \mathrm{NS}\right)$, sex $\mathrm{X}$ treatment $\left(\mathrm{F}_{1,113}=\right.$ $1.487, \mathrm{NS})$, treatment $\mathrm{X}$ age $\left(\mathrm{F}_{2,113}=0.817, \mathrm{NS}\right)$ or sex $\mathrm{X}$ treatment $X$ age $\left(F_{2,113}=1.193, N S\right)$ interactions. Likewise, ANOVA of the data failed to reveal any significant effect of prenatal LPS treatment upon the number of male $\left(\mathrm{F}_{1,30}=0.616, \mathrm{NS}\right)$ or female $\left(\mathrm{F}_{1,30}=2.261, \mathrm{NS}\right)$ pups born (data not shown).

\section{Effect of Antipsychotics upon PPI Deficit Induced by Prenatal LPS Exposure}

We studied in offspring rats of 100 days of age, the effect of acute administration $(0.1 \mathrm{mg} / \mathrm{kg}$, s.c. $)$ of the typical antipsychotic haloperidol (HAL) upon PPI deficit induced by prenatal LPS exposure (Figure 2). Prenatal LPS treatment significantly reduced basal startle amplitude in male rats $(p<.001)$, without affecting female rats (Figure 2, Panel A). A significant prenatal treatment $X$ antipsychotic treatment interaction upon PPI was observed $\left(\mathrm{F}_{1,101}=17.353, p<.001\right)$. HAL significantly facilitated PPI in control animals $\left(\mathrm{F}_{1,50}=12.300\right.$, $p<.001$ ) as previously described (Varty and Higgins 1995; Depoortere et al. 1997). Subsequent statistical analysis revealed that HAL significantly reversed the PPI deficit induced by prenatal administration of LPS $\left(\mathrm{F}_{1,51}=58.824, p<.001\right)$ (Figure 2, Panels B and C).

We also studied the effect of acute administration (5 $\mathrm{mg} / \mathrm{kg}$, i.p.) of the atypical antipsychotic clozapine (CZP) (Figure 3). In control rats, CZP significantly decreased basal startle response $\left(\mathrm{F}_{1,36}=9.469, p<.01\right)$ (Figure 3, Panel A) an effect of the drug previously reported (Depoortere et al. 1997). As in the previous experiments, prenatal LPS treatment significantly reduced the percentage of PPI $\left(\mathrm{F}_{1,87}=6.225, p<.05\right)$. A significant prenatal treatment $\mathrm{X}$ antipsychotic treatment effect was observed $\left(\mathrm{F}_{1,87}=17.774, p<.001\right)$. CZP significantly reversed PPI deficit induced by prenatal administration of LPS $\left(\mathrm{F}_{1,51}=9.099, p<.01\right)$ (Figure 3, Panels B and C).

These data clearly indicate that both, the typical antipsychotic HAL as well as the atypical CZP reverse the sensorimotor gating deficit observed in adult rats prenatally exposed to LPS treatment.

\section{Effect of Prenatal LPS Exposure upon Cytokine Serum Levels}

Subcutaneous administration of a single dose of $1 \mathrm{mg} /$ $\mathrm{kg}$ of LPS to adult female rats significantly increased se- 


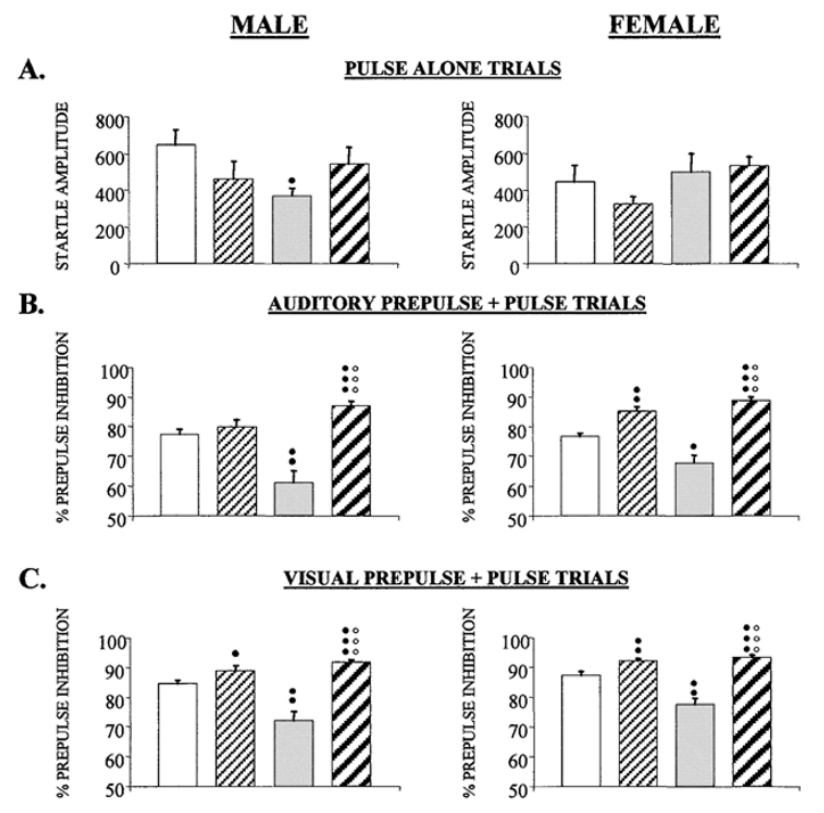

$\square$ CONTROL + VEH $\square$ CONTROL + HAL $\square$ LPS + VEH $\square$ LPS + HAL

Figure 2. Effect of haloperidol (HAL) on startle amplitude (A), auditory (B) and visual (C) prepulse inhibition in prenatally LPS-exposed male and female adult (100 or 300 days of age) rats. LPS-exposed groups consisted of offspring rats whose mothers were subjected to administration of a dose of $1 \mathrm{mg} / \mathrm{kg}$ (s.c.) of LPS on alternate days during pregnancy. Control groups consisted of offspring rats whose mothers were submitted to the same treatment schedule with saline. HAL $(0.1 \mathrm{mg} / \mathrm{kg}$, s.c.) or vehicle (VEH) were administered $30 \mathrm{~min}$ before PPI testing. Results are expressed as mean \pm S.E.M. ( $\mathrm{n}=12-14$ rats per group). ${ }^{\prime} p<.05 ;{ }^{\prime} p<.01 ; \cdots p<$ .001 vs. corresponding CONTROL + VEH group; ${ }^{\circ 00} p<$ .001 vs. corresponding LPS + VEH group (Student-Newman-Keuls $t$-test following significant ANOVA).

rum levels of interleukin- $1 \beta(\mathrm{IL}-1 \beta)\left(\mathrm{F}_{3,72}=3.586, p<.05\right)$, IL-6 $\left(\mathrm{F}_{3,72}=30.799, p<.001\right)$, and IL-2 $\left(\mathrm{F}_{3,72}=9.954, p<\right.$ $.001)$, as well as of corticosterone $\left(\mathrm{F}_{3,72}=30.833, p<.001\right)$ in a time course of two hours (data not shown).

Prenatal LPS exposure also influences the immune system later in life (Figure 4). Such treatment did not affect serum levels of IL-1 $\beta\left(\mathrm{F}_{1,58}=0.049, \mathrm{NS}\right)$ or corticosterone $\left(\mathrm{F}_{1,58}=0.017, \mathrm{NS}\right)$ in adult offspring. However, serum levels of IL-6 and IL-2 were significantly modified in the same animals $\left(\mathrm{F}_{1,58}=11.523, p<.01 ; \mathrm{F}_{1,58}=\right.$ $14.592, p<.001$, respectively). Post hoc tests indicated that serum IL-6 levels were significantly elevated in LPS-exposed male and female offspring of 100 days of age, whereas serum IL-2 levels were significantly elevated in LPS-exposed male offspring of 100 or 300 days of age and in LPS-exposed female offspring of 300 days of age.
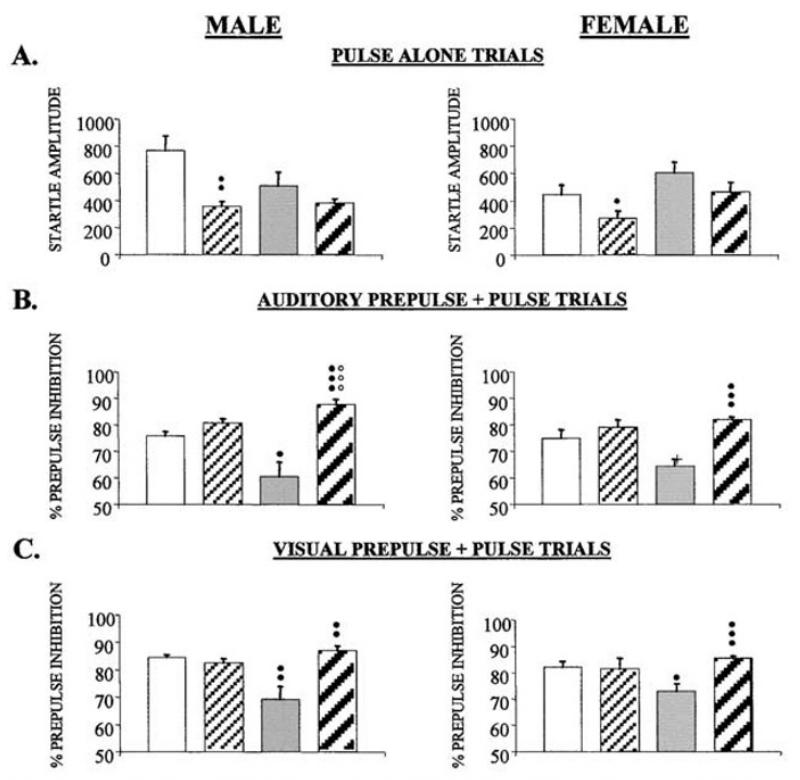

$\square$ CONTROL + VEH $\square$ CONTROL + CZP $\square$ LPS + VEH $\square \mathrm{LPS}+\mathrm{CZP}$

Figure 3. Effect of clozapine (CZP) on startle amplitude (A), auditory (B) and visual (C) prepulse inhibition in prenatally LPS-exposed male and female adult (100 or 300 days of age) rats. LPS-exposed groups consisted of offspring rats whose mothers were subjected to administration of a dose of $1 \mathrm{mg} / \mathrm{kg}$ (s.c.) of LPS on alternate days during pregnancy. Control groups consisted of offspring rats whose mothers were submitted to the same treatment schedule with saline. CZP $(5 \mathrm{mg} / \mathrm{kg}$, i.p.) or vehicle (VEH) were administered 30 min before PPI testing. Results are expressed as mean \pm S.E.M. ( $\mathrm{n}=12-14$ rats per group). $p<.05 ; " \cdots<.01 ; \cdots p<$ .001 vs. corresponding CONTROL + VEH group; ${ }^{\circ} p<$ .001 vs. corresponding LPS + VEH group (Student-Newman-Keuls $t$-test following significant ANOVA).

\section{Prenatal LPS Exposure Induces Histopathological Alterations in Adult Brain}

Astrocytes and microglia in brain sections from control males displayed the characteristic appearance of resting mature cells (Figure 5). There were no signs of glial reactivity and major histocompatibility complex class II molecules (MHC class II) only expressed in microglia located in circumventricular organs and meningeal leukocytes. In contrast, adult male rats submitted to prenatal LPS treatment showed morphological signs of astroglial and microglial reactivity (Figure 5), and some hematogenous leukocytes and microglial cells expressed MHC II molecules (Figure 6). Both glial reactivity and MHC class II expression were restricted to specific brain areas. In gray matter, affected areas were nucleus accumbens, ventral pallidum, olfactory tubercle, bed nucleus of the stria terminalis and septal, en- 
MALE

FEMALE

\section{$\underline{\text { IL-1 } \beta}$}
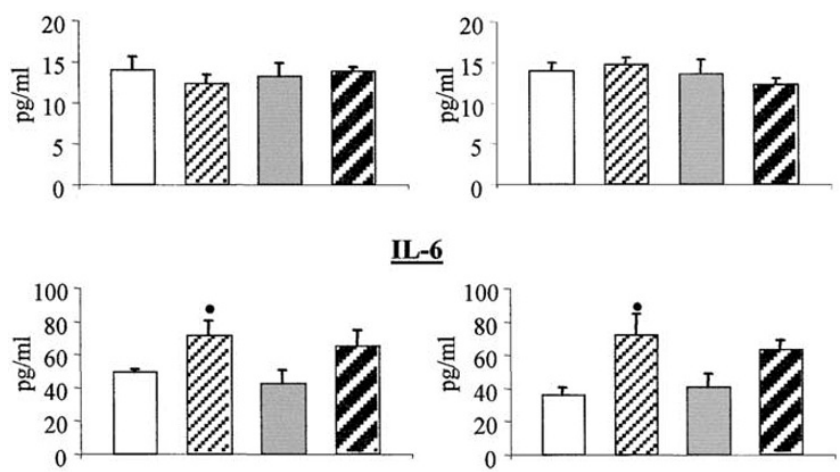

$\underline{\text { IL-6 }}$

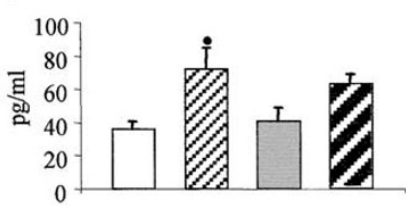

$\underline{\text { IL-2 }}$
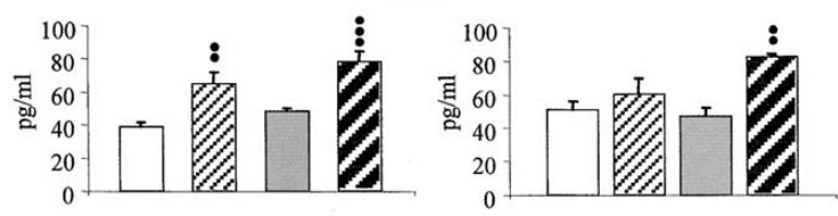

CORTICOSTERONE
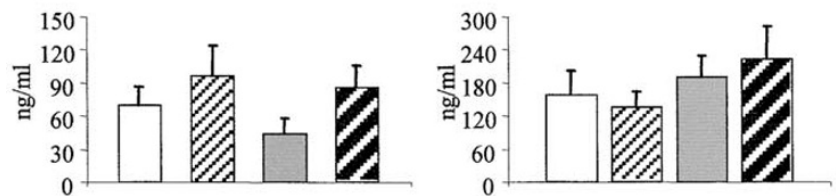

CONTROL 100 DAYS $\square$ L. LPS 100 DAYS

CONTROL 300 DAYS LPS 300 DAYS

Figure 4. Effect of prenatal administration of LPS on serum cytokines and corticosterone levels in male and female adult (100 or 300 days of age) rats. LPS-exposed groups consisted of offspring rats whose mothers were subjected to administration of a dose of $1 \mathrm{mg} / \mathrm{kg}$ (s.c.) of LPS on alternate days during pregnancy. Control groups consisted of offspring rats whose mothers were submitted to the same treatment schedule with saline. Data are the mean \pm S.E.M. of eight animals per group. $p<.05 ;{ }^{\prime} p<.01 ; \cdots p<.001$ vs. corresponding CONTROL group (Student-Newman-Keuls $t$-test following significant ANOVA).

dopiriform and amygdaloid nuclei. Effects in white matter were found in the anterior commissure, corpus callosum, stria terminalis and capsula interna. In addition, we observed an increased tyrosine hydroxylase (TH) immunoreactivity in some affected areas, particularly in the shell of the nucleus accumbens (ACC) and in the adjacent bed nucleus of the stria terminalis (BNST) (Figure 7). The quantification of the density of $\mathrm{TH}$ immunoreactivity in these nuclei revealed that there was a significant effect of prenatal LPS treatment $\left(\mathrm{F}_{1,8}=64.742, p<.001\right.$ for ACC; $\mathrm{F}_{1,8}=62.068, p<.001$ for BNST). No effect of age $\left(\mathrm{F}_{1,8}=0.014\right.$, NS for ACC; $\mathrm{F}_{1,8}=4.638$, NS for BNST) or age $\mathrm{X}$ treatment interac-

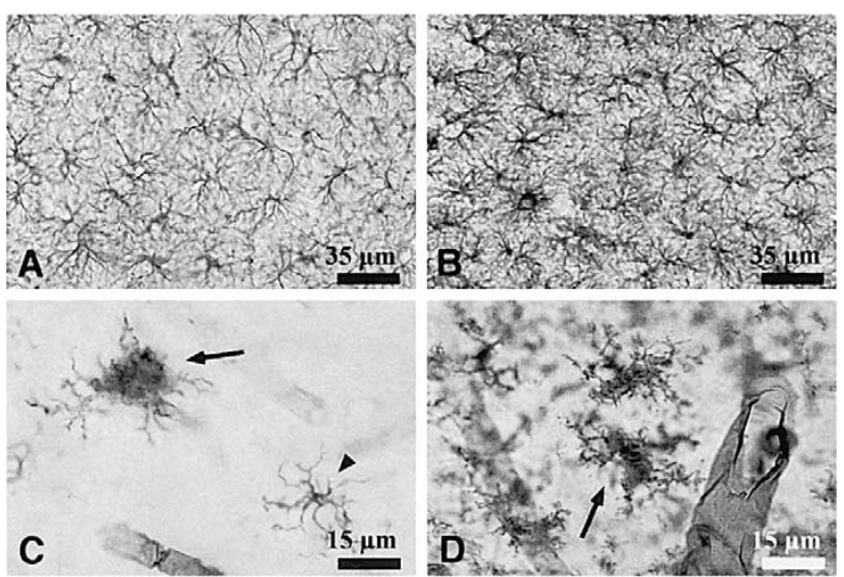

Figure 5. Effect of prenatal administration of LPS on astrocytes (A and B) and microglia (C and D) in brain sections from adult (100 and 300 days of age) male rats. Astrocytes in the amygdala of 100-day control (A) and LPS-exposed (B) rats were visualized by GFAP immunohistochemistry. Note that astrocytes in LPS-exposed rats display increased GFAP immunoreactivity respect to the control. Microglial cells showing morphological signs of reactivity in LPS-exposed rats were visualized in the nucleus accumbens of 100-day rats (C) and in the bed nucleus of the stria terminalis of 300-day rats (D) by tomato lectin histochemistry. Note that both reactive microglial cells (arrows) and microglial cells devoid of apparent sign of reactivity (arrowhead) were found in these areas. Note also that blood vessel endothelial cells, in addition to microglia, display tomato lectin reactivity.

tion $\left(\mathrm{F}_{1,8}=0.697\right.$, NS for ACC; $\mathrm{F}_{1,8}=0.836$, NS for BNST) were observed. Data revealed that TH immunoreactivity was elevated vs. control in LPS-exposed rats by $52.42 \%$ (100 days) and $40.82 \%$ (300 days) for ACC and 36.05\% (100 days) and 42.77\% (300 days) for BNST.

Astrogliosis in affected areas was moderate (300-day group of rats) to subtle (100-day group of rats) and was evident as slightly hypertrophied astrocytes with increased GFAP immunoreactivity (Figure 5, Panels A and B). Microglial reactivity was evidenced by an increase in lectin binding, but morphological signs of reactivity were subtle. In the shell of the nucleus accumbens and in the bed nucleus of the stria terminalis some microglial cells showing the characteristic features of reactive microglia (enlargement of the cell body and retraction of cell processes) were found in both groups of animals, but more frequently in the oldest (Figure 6, Panels C and D).

Expression of MHC class II molecules by microglia and leukocytes was a prominent feature in prenatally LPS-exposed rats (Figure 7). MHC class II-positive microglia were parenchymatic, non-perivascular cells and were predominantly found in white matter areas. In 

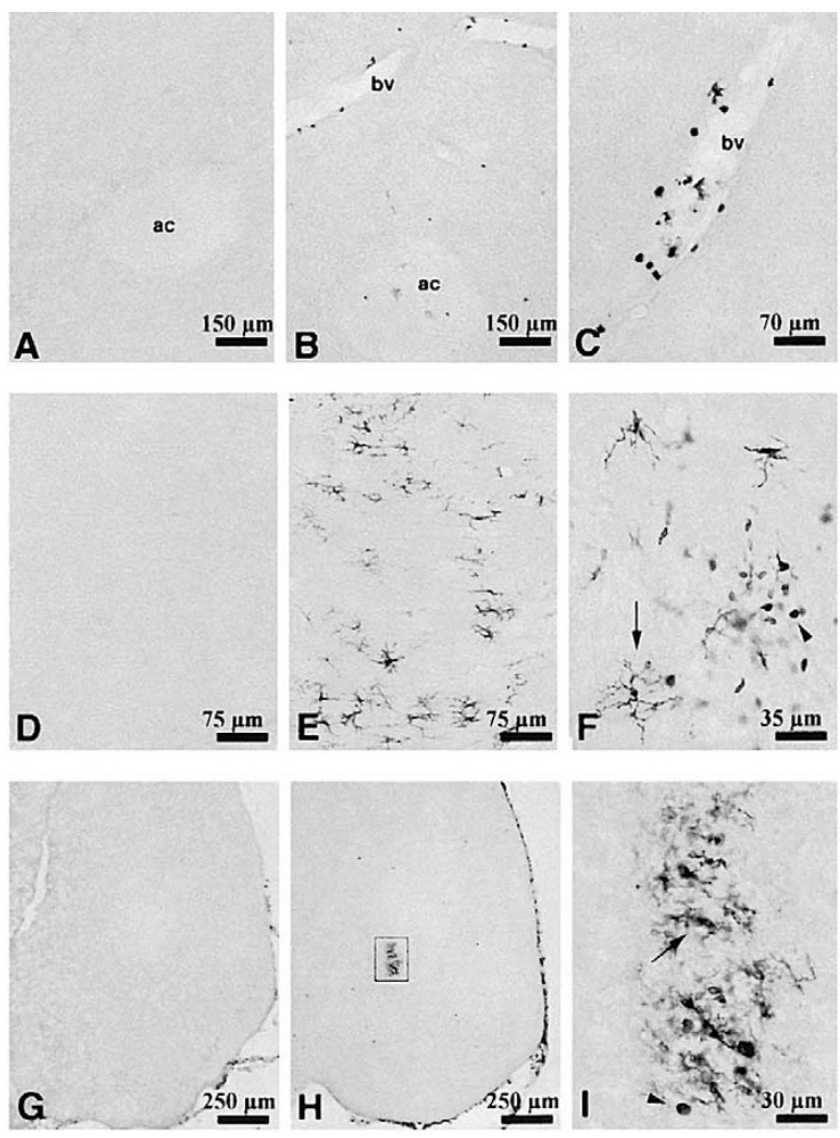

Figure 6. Effect of prenatal administration of LPS on MHC class II expression in brain sections from adult (100 and 300 days of age) male rats. No MHC class II immunoreactivity was found in the brain parenchyma of control rats: nucleus accumbens (A), internal capsule (D) and olfactory peduncle (G) of control rats of 100 days of age. In contrast, both MHC class II-positive leukocytes and microglia were found in adult rats whose mother received LPS during pregnancy (B, C, E, F, H, I). B) leukocytes in the nucleus accumbens and anterior commissure (ac) of 100-day LPS rats. Note that some leukocytes were found in relation to blood vessels (bv). C: leukocytes adhered to the wall of a blood vessel in the ventral pallidum of 300-day LPS rats. E: MHC class IIpositive microglia in the internal capsule of 100-day LPSexposed rats. F: at a higher magnification respect to photomicrograph (E), MHC class II-positive microglia (arrow) and leukocytes (arrowhead) were found in the internal capsule of 300-day LPS rats. H: MHC class II- positive cells in the olfactory peduncle of 100-day LPS rats. I: High magnification inset in photomicrograph $(\mathbf{H})$ showing the presence of MHC class II-positive leukocytes (arrowhead) and processbearing microglia (arrow).

contrast, leukocytes appeared adhered to the vascular walls or infiltrated in the nervous parenchyma, and were found in both the affected gray and white matter areas. The number of leukocytes was higher in the 100 than in the 300-day group of LPS-exposed rats.

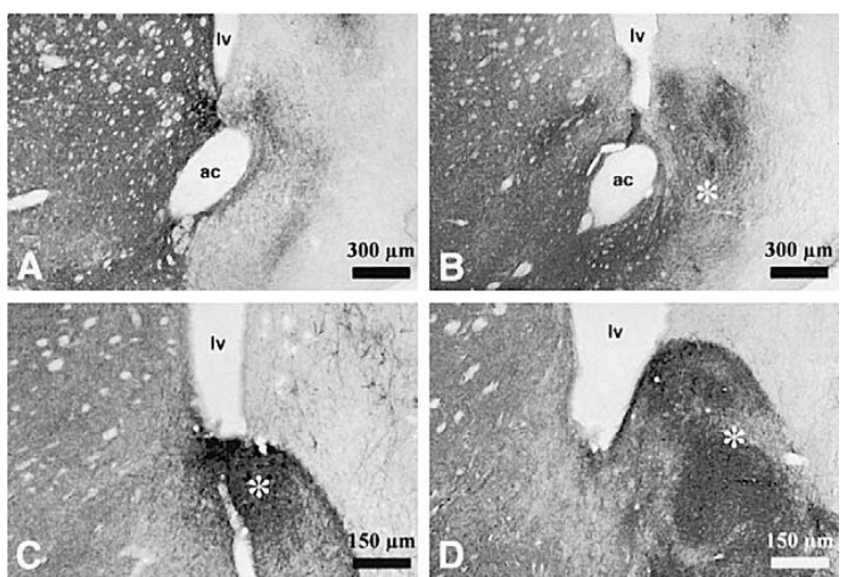

Figure 7. Effect of prenatal administration of LPS on tyrosine hydroxylase (TH) immunoreactivity in brain sections from adult (100 and 300 days of age) male rats. Nucleus accumbens of control (A) and LPS (B) rats of 100 days of age. Note that TH immunoreactivity in the shell of the nucleus accumbens in LPS-exposed rats $\left(^{*}\right)$ is increased respect to control rats. The shell of the nucleus accumbens (C) and the bed nucleus of the stria terminalis (D) also show increased tyrosine hydroxylase immunoreactivity in 300day LPS-exposed rats. lv, lateral ventricle; ac, anterior commissure; * denotes areas showing increased immunoreactivity respect to controls.

\section{DISCUSSION}

Hypotheses on the etiology of schizophrenia emphasize the important role of perinatal insults in predisposing individuals to the development of the psychiatric disease. Our data demonstrate for the first time that prenatal LPS immune challenge induces PPI deficit later in life. Interestingly, LPS-exposed female rats manifested the PPI disruption later than LPS-exposed male rats, which resembles the sex differences in age at onset of the disorder reported in schizophrenic patients (Loranger 1984). Other perinatal interventions in rats are known to influence PPI (Schwarzkopf et al. 1992; Varty and Higgins 1995; Ellenbroek et al. 1998; Black et al. 1999). Therefore, our data further support the critical influence of perinatal events on the information processing of an individual at adult age.

Since antipsychotics reverse the disruption in PPI induced by isolation rearing (Varty and Higgins 1995; Bakshi et al. 1998) or maternal deprivation (Ellenbroek et al. 1998), it has been suggested that those animal models may become useful for studying the influence of aberrant CNS development on information processing in adulthood and for identifying potential novel antipsychotic drugs. It is well documented that while both typical and atypical antipsychotics restore PPI in DA agonist-treated rats, only atypical antipsychotics restore PPI in rats treated with NMDA antagonists (Swerdlow 
and Geyer 1998). In the present study, the typical antipsychotic haloperidol, as well as the atypical clozapine were effective in restoring the PPI deficit observed in adult offspring of rats submitted to LPS treatment during pregnancy. These findings suggest that PPI-induced deficit by prenatal LPS exposure is likely related to alterations in brain dopaminergic function. In fact, an increased TH immunoreactivity was observed in the shell of the nucleus accumbens and in the adjacent bed nucleus of the stria terminalis of rats prenatally treated with LPS, thus suggesting an increased catecholaminergic, perhaps dopaminergic, activity. This may account for the observed diminished PPI since nucleus accumbens hyperdopaminergia disrupts PPI (Swerdlow and Geyer 1998).

As mentioned earlier, prenatal exposure to common infections or influenza may increase the risk for the later development of schizophrenia. It has been reported (Rothschild et al. 1999) that rats infected neonatally with rat cytomegalovirus exhibit a deficit in PPI but only upon dopamine stimulation. Neural migration abnormalities in the brain of neonatal mice that were prenatally exposed to human influenza virus have been reported (Fatemi et al. 1999). Under the conditions used in the present work, acute subcutaneous administration of a dose of $1 \mathrm{mg} / \mathrm{kg}$ of LPS to adult female rats significantly increased serum levels of IL-1 $\beta$, IL- 6 and IL-2 as well as of corticosterone. Therefore, the pregnant rats were submitted to the well-documented LPS-induced immune challenge. Although LPS could induce effects on maternal rearing, the data on serum corticosterone and animal weight in adult offspring make this explanation unlikely as a major source of PPI disruption. Thus, it could be speculated that the sensorimotor gating and immune alterations observed in LPS-exposed rats might be due to disturbances in brain neurodevelopment, consequence of the prenatal LPS-induced immune challenge.

Prenatal LPS exposure also influenced the immune system later in life, inducing in adult offspring significant increases of IL-2 and IL-6 serum levels. Although in schizophrenic patients immune abnormalities have been reported, the lack of consistent replicability of the findings and the relatively modest degree of the alterations have made it impossible to impute a particular immune dysfunction to the pathophysiology of schizophrenia (Kirch 1993). Cytokine abnormalities that have been replicated in studies of schizophrenic patients include increased serum-soluble interleukin-2 receptors (Maes et al. 1995; Akiyama 1999) and serum IL-6 levels (Ganguli et al. 1994; Maes et al. 1995; Akiyama 1999). Contradictory results have been reported on IL-2 serum levels (Gattaz et al. 1992; Kim et al. 1998). Thus, in the present study, sensorimotor gating deficient LPSexposed rats displayed, to some extend, similar immune alterations as those reported in schizophrenic patients.
Peripheral IL-6 may cross the blood-brain barrier by an active transport mechanism (Banks et al. 1994) acting in the CNS through specific receptors (Schöbitz et al. 1993). Lymphocyte-derived IL-2 has also been suggested to cross the intact blood brain barrier (Waguespack et al. 1994) and may gain access to IL-2 receptors on neuronal and glial cells (Araujo et al. 1989; Sawada et al. 1995). Interestingly, IL-2 in the rodent brain is expressed in selected regions, including the hippocampus, frontoparietal cortex, striatum, and septum (Araujo et al. 1989), brain areas directly implicated in the cortico-striato-pallido-pontine gating circuitry (Swerdlow and Geyer 1998). Also of interest is the ability of IL-2 to suppress afferent sensory transmission in the primary somatosensory cortex (Park et al. 1995), suggesting a role for IL-2 in the gating of incoming sensory information. There are also clinical observations on IL-2 human therapy provoking neuropsychological as well as neurophysiological disturbances (Denicoff et al. 1987). Therefore, the disrupted PPI observed in prenatally LPS-exposed rats might be attributable to CNS disturbances provoked by the increased IL-2 and/or IL-6 circulating levels.

Brain sections from LPS-exposed male rats revealed that basal forebrain areas involved in the above mentioned sensorimotor gating circuitry displayed histopathological features. They consist of mild astrocyte hypertrophy, microglial activation and presence of hematogenous leukocytes. Astrocytes and microglia are sensors for pathological events in the CNS and become activated in response to even subtle changes in brain homeostasis (Bruce-Keller 1999). Furthermore, infiltrated leukocytes and activated astrocytes and microglia are important sources of cytokines in the CNS (Becher et al. 2000). In schizophrenia, mild astrocyte hypertrophy (but not hyperplasia), microglial activation and expression of MHC class II molecules have been described (Arnold et al. 1996; Bayer et al. 1999; Radewicz et al. 2000).

It is important to note that sensorimotor gating deficits in schizophrenic patients reflect longitudinal and complex interactions of genetic, developmental, and environmental factors. Although no animal model can fully reproduce the perceptual, cognitive and emotional features of the human illness (Lipska and Weinberger 2000), the prenatal immune challenge model here described, based on a hypothetical causative factor in schizophrenia, reproduces to some extent behavioral and biological phenomena relevant to schizophrenia: (1) Prenatally LPS-exposed rats displayed a clear sensorimotor gating deficit, which, being qualitatively similar to the disturbance seen in schizophrenic patients, is overcome by antipsychotic treatment. (2) Several histopathological alterations are observed in brain areas directly related to the sensorimotor gating circuitry, and, to some extent, resemble those described in schizophre- 
nia. (3) Adult offspring of rats receiving LPS during pregnancy showed elevated circulating levels of IL-2 and IL-6, which coincide with some of the immunological alterations described in schizophrenic patients.

Our findings, without suggesting a single cause in schizophrenia, are of further support for the critical influence of perinatal immune events on the information processing of an individual at adult age and might be of relevance for the understanding of, at least some, the proposed neurobiological mechanisms underlying the phenomenology of schizophrenia.

\section{ACKNOWLEDGMENTS}

This work was supported by grants from the CICYT (PM-98/ 014) and from the CAM (08.5/0039/98). We thank Concha García for her technical help.

\section{REFERENCES}

Adams W, Kendell RE, Hare EH, Munk-Jorgensen P (1993): Epidemiological evidence that maternal influenza contributes to the aetiology of schizophrenia: An analysis of Scottish, English, and Danish data. Br J Psychiatry 163:522-534

Akiyama K (1999): Serum levels of soluble IL-2 receptor alpha, IL-6 and IL-1 receptor antagonist in schizophrenia before and during neuroleptic administration. Schizophr Res 37:97-106

Andersson J, Nagy S, Björk L, Abrams J, Holm S, Andersson U (1992): Bacterial toxin-induced cytokine production studied at the single-cell level. Immunol Rev 127:69-96

Anisman H, Kokkinidis L, Borowski T, Merali Z (1998): Differential effects of interleukin (IL)-1 $\beta$, IL-2 and IL-6 on responding for rewarding lateral hypothalamic stimulation. Brain Res 779:177-187

Araujo DM, Lapchak PA, Collier B, Quirion R (1989): Localization of interleukin-2 immunoreactivity and interleukin-2 receptors in the rat brain: interaction with the cholinergic system. Brain Res 498:257-266

Arnold SE, Franz BR, Trojanowski JQ, Moberg PJ, Gur RE (1996): Glial fibrillary acidic protein-immunoreactive astrocytosis in elderly patients with schizophrenia and dementia. Acta Neuropathol 91:269-277

Bakshi VP, Swerdlow NR, Braff DL, Geyer MA (1998): Reversal of isolation rearing-induced deficits in prepulse inhibition by seroquel and olanzapine. Biol Psychiatry 43:436-445

Banks WA, Kastin AJ, Gutierrez EG (1994): Penetration of interleukin- 6 across the murine blood-barrier. Neurosci Lett 179:53-56

Bayer TA, Buslei R, Havas L, Falkai P (1999): Evidence for activation of microglia in patients with psychiatric illnesses. Neurosci Lett 271:126-128

Becher B, Prat A, Antel JP (2000): Brain-immune connection: immuno-regulatory properties of CNS-resident cells. Glia 29:293-304
Berkenbosch F, Van Oers J, Del Rey A, Tildres F, Besedovsky H (1987): Corticotrophin-releasing factor-producing neurons in the rat activated by interleukin-1. Science 238:524-526

Besedovsky HO, del Rey A, Sorkin E, Dinarello CA (1986): Immunoregulatory feed-back between interleukin-1 and glucocorticoid hormones. Science 233:652-654

Black MD, Selk DE, Hitchcock JM, Wettstein JG, Sorensen SM (1999): On the effect of neonatal nitric oxide synthase inhibition in rats: a potential neurodevelopmental model of schizophrenia. Neuropharmacology 38:12991306

Braff DL, Stone C, Callaway E, Geyer M, Glick ID, Bali L (1978): Prestimulus effects on human startle reflex in normalise and schizophrenics in normals. Psychophysiology 15:339-343

Bruce-Keller AJ (1999): Microglial-neuronal interactions in synaptic damage and recovery. J Neurosci Res 58:191-201

Cambronero JC, Rivas FJ, Borrell J, Guaza C (1992): IL-2 increases CRF secretion from superfused rat hypothalami. Influence of glucocorticoids. Endocrinology 131:677-683

Campeu S, Davis M (1995): Prepulse inhibition of the acoustic startle reflex using visual and auditory prepulses: disruption by apomorphine. Psychopharmacology 117:267-274

Castellanos FX, Fine EJ, Kaysen D, Marsh WL, Rapoport JL, Hallet M (1996): Sensorimotor gating in boys with Tourette's syndrome and ADHD: Preliminary results. Biol Psychiatry 39:33-41

del Cerro S, Borrell J (1990): Interleukin-1 affects the behavioral despair response in rats by an indirect mechanism which requires endogenous CRF. Brain Res 528:162-164

Denicoff KD, Rubinow DR, Papa MZ, Simpson I, Seipp LA, Lotze MT, Chang AE, Rosenstein D, Rosenberg SA (1987): The neuropsychiatric effects of treatment with interleukin-2 and lymphokine-activated killer cells. Ann Int Med 107:293-300

Depoortere R, Perrault G, Sanger DJ (1997): Potentiation of prepulse inhibition of the startle reflex in rats: pharmacological evaluation of the procedure as a model for detecting antipsychotic activity. Psychopharmacology 132:366-374

Dinarello CA (1984): Interleukin-1 and the pathogenesis of the acute-phase response. N Engl J Med 311:1413-1422

Ellenbroek BA, van der Kroonenberg PTJM, Cools AR (1998): The effects of an early stressful life event on sensorimotor gating in adult rats. Scizophr Res 30:251-260

Fatemi SH, Emamian ES, Kist D, Sidwell RW, Nakajima K, Akhter P, Shier S, Bailey K (1999): Defective corticogenesis and reduction in Reelin immunoreactivity in cortex and hippocampus of prenatally infected neonatal mice. Mol Psychiatry 4:145-154

Ganguli R, Yang ZW, Shurin G, Chengappa KN, Brar JS, Gubbi AV, Rabin BS (1994): Serum interleukin-6 concentration in schizophrenia: elevation associated with duration of illness. Psychiatry Res 51:1-10

Gattaz WF, Dalgalarrondo P, Schröder HC (1992): Abnormalities in serum concentrations of interleukin-2, interferon-alpha and interferon-gamma in schizophrenia not detected. Schizophr Res 6:237-241 
Grillon C, Morgan CA, Southwick SM, Davis M, Charney DS (1996): Baseline startle amplitude and prepulse inhibition in Vietnam veterans with posttraumatic stress disorder. Psychiatry Res 64:169-178

Hanisch UK, Neuhaus J, Rowe W, Van Rossum D, Möller T, Kettenmann H, Quirion R (1997): Neurotoxic consequences of central long-term administration of interleukin-2 in rats. Neuroscience 79:799-818

Hoffman HS, Ison JR (1980): Reflex modification in the domain of startle: I. Some empirical findings and their implications for how the nervous system processes sensory input. Psychol Rev 2:175-189

Kent S, Bluthe RM, Kelley KW, Dantzer R (1992): Sickness behavior as a new target for drug development. Trends Pharmacol Sci 12:24-28

Kim YK, Lee MS, Shu KY (1998): Decreased interleukin-2 production in Korean schizophrenic patients. Biol Psychiatry 43:701-704

Kirch DG (1993): Infection and autoimmunity as etiologic factors in schizophrenia: A Review and Reappraisal. Schizophr Bull 19:355-368

Kumari V, Soni W, Sharma T (1999): Normalization of information processing deficits in schizophrenia with clozapine. Am J Psychiatry 156:1046-1051

Linthorst ACE, Flachskamm C, Holsboer F, Reul JMHM (1994): Local administration of recombinant human interleukin-1 $\beta$ in the rat hippocampus increases serotoninergic neurotransmission, hypothalamic-pituitaryadrenocortical axis activity, and body temperature. Endocrinology 135:520-532

Linthorst ACE, Flachskamm C, Müleer-Preuss P, Holsboer F, Reul JMHM (1995): Effect of bacterial endotoxin and Interleukin 1- $\beta$ on hippocampal serotoninergic neurotransmission, behavioral activity, and free corticosterone levels: An in vivo microdialysis study. J Neurosci 15:2920-2934

Lipska BK, Weinberger DR (2000): To model a psychiatric disorder in animals. Schizophrenia as a reality test. Neuropsychopharmacology 23:223-239

Loranger AW (1984): Sex differences in age of onset of schizophrenia. Arch Gen Psychiat 41:157-161

Maes M, Meltzer HY, Buckley P, Bosmans E (1995): Plasmasoluble interleukin-2 and transferrin receptor in schizophrenia and major depression. Eur Arch Psychiatry Clin Neurosci 244:325-329

Mansbach RS, Geyer MA, Braff DL (1988): Dopaminergic stimulation disrupts sensorimotor gating in the rat. Psychopharmacology 94:507-514

Mednick SA, Machon RA, Huttunen M, Bone D (1988): Adult schizophrenia following prenatal exposure to an influenza epidemic. Arch Gen Psychiatry 45:189-192

Molina-Holgado F, Guaza C (1996): Endotoxin administration induces differential neurochemical activation of the rat brain stem nuclei. Brain Res Bull 40:151-156

Mortensen PB, Pedersen CB, Westergaard T, Wohlfahrt J, Ewald H, Mors O, Andersen PK, Melbye M (1999): Effects of family history and place and season of birth on the risk of schizophrenia. N Engl J Med 340:603-608

O'Callaghan E, Sham P, Takei N, Glover G, Murray RM (1991): Schizophrenia after prenatal exposure to 1957 A2 influenza epidemic. Lancet 337:1248-1250
Otero GC, Merrill JE (1994): Cytokine receptors on glial cells. Glia 11:117-128

Park HJ, Won CK, Pyun KH, Shin HC (1995): Interleukin-2 suppresses afferent sensory transmission in the primary somatosensory cortex. NeuroReport 6:1018-1020

Pauli S, Linthorst ACE, Reul JMHM (1998): Tumor necrosis factor- $\alpha$ and interleukin-2 differentially affect hippocampal serotoninergic neurotransmission, behavioural activity, body temperature and hypothalamic-pituitaryadrenocortical axis activity in the rat. Eur J Neurosci 10:868-878

Plata-Salamán CR (1991): Immunoregulators in the nervous system. Neurosci Biobehav Rev 15:185-215

Pollmächer T, Schreiber W, Gudewill S, Vedder H, Fassbender K, Wiedemann K, Trachsel 1, Galanos C, Holsboer F (1993): Influence of endotoxin on nocturnal sleep in humans. Am J Physiol 264: R1077-1083

Raber J, Sorg O, Horn TF, Yu N, Koob GF, Campbell IL, Bloom FE (1998): Inflammatory cytokines: putative regulators of neuronal and neuro-endocrine function. Brain Res Rev 26:320-326

Radewicz K, Garey LJ, Gentleman SM, Reynolds R (2000): Increase in HLA-DR immunoreactive microglia in frontal and temporal cortex of chronic schizophrenics. J Neuropathol Exp Neurol 59:137-150

Raedler TJ, Knable MB, Weinberger DR (1998): Schizophrenia as a developmental disorder of the cerebral cortex. Curr Opinion Neurobiol 8:157-161

Rothschild DM, O'Grady M, Wecker L (1999): Neonatal cytomegalovirus decreases prepulse inhibition in adult rats: Implications for schizophrenia. J Neurosci Res 57:429-434

Rothwell NJ, Hopkins SJ (1995): Cytokines and the nervous system: II. Action and mechanisms of action. Trends Neurosci 18:130-136

Sawada M, Suzumura A, Marunouchi T (1995): Induction of interleukin-2 receptor in mouse microglia. J Neurochem 64:1973-1979

Schöbitz B, De Kloet ER, Sutano W, Holsboer F (1993): Cellular localization of interleukin 6 mRNA and interleukin 6 receptor mRNA in rat brain. Eur J Neurosci 5: 1426-1435

Schwarzkopf SB, Mitra T, Bruno JP (1992): Sensory gating in rats depleted of dopamine as neonates: potential relevance to findings in schizophrenic patients. Biol Psychiatry 31:759-773

Swerdlow NR, Benbow CH, Zisook S, Geyer MA, Braff DL (1993): A preliminary assessment of sensorimotor gating in patients with obsessive compulsive disorder. Biol Psychiatry 33:298-301

Swerdlow NR, Braff DL, Taaid N, Geyer MA (1994): Assessing the validity of an animal model of deficient sensorimotor gating in schizophrenic patients. Arch Gen Psychiatry 51:139-154

Swerdlow NR, Paulsen J, Braff DL, Butters N, Geyer MA, Swenson MR (1995): Impaired prepulse inhibition of acoustic and tactile startle response in patients with Huntington' s disease. J Neurol Neurosurg Psychiatry 58:192-200

Swerdlow NR, Geyer MA (1998): Using an animal model of 
deficient sensorimotor gating to study the pathophysiology and new treatments of schizophrenia. Schizophr Bull 24:285-301

Swerdlow NR, Braff DL, Geyer MA (1999): Cross-species studies of sensorimotor gating of the startle reflex. Ann N Y Acad Sci 877:202-216

Torrey EF, Torrey BB, Peterson MR (1977): Seasonality of schizophrenic births in the United States. Arch Gen Psychiatry 34:1065-1070

Varty GB, Higgins GA (1995): Examination of drug-induced and isolation-induced disruptions of prepulse inhibition as models to screen antipsychotic drugs. Psychopharmacology 122:15-26

Waguespack PJ, Banks WA, Kastin AJ (1994): Interleukin-2 does not cross the blood-brain barrier by a saturable transport system. Brain Res Bull 34:103-109

Weike AI, Bauer U, Hamm AO (2000): Effective neuroleptic medication removes prepulse inhibition deficits in schizophrenia patients. Biol Psychiatry 47:61-70

Weinberger DR (1996): On the plausibility of "the neurodevelopmental hypothesis" of schizophrenia. Neuropsychopharmacology 14:1S-11S

Zalcman S, Murray L, Dyck DG, Greenberg AH, Nance DM (1998): Interleukin-2 and -6 induce behavioral-activating effects in mice. Brain Res 811:111-121

Zao B, Schwartz JP (1998): Involvement of cytokines in normal CNS development and neurological diseases: Recent progress and perspectives. J Neurosci Res 52:7-16 